\title{
Motivated level of construal: How temperature affects the construal level of state-relevant stimuli
}

\author{
Jochim Hansen ${ }^{1}\left[\right.$ ] Janina Steinmetz ${ }^{2}$
}

Published online: 23 January 2019

(c) The Author(s) 2019

\begin{abstract}
Motivation affects perception, for example when people overestimate the psychological proximity of goal-relevant objects. Additionally, proximity maps onto more concrete (vs. abstract) construal. Following from these findings, we predicted that people construe goal-relevant stimuli more concretely than goal-irrelevant stimuli. Three experiments tested this idea (total $N=305$ ). In Experiment 1, people who were warm (versus cold) grouped cold drinks into more and narrower categories, as cold drinks served their goal to cool off. In Experiment 2, heat simulations lead people to represent cooling actions (e.g., drinking cold water) in more concrete terms (i.e., as for how instead of why), whereas cold simulations lead people to represent warming actions in more concrete terms. In Experiment 3, participants evaluated heaters and ventilators based on concrete (i.e., single reviews) instead of abstract product information (i.e., overall ratings) if the product was motivationally relevant. These findings show that basic motivations can shift the level of abstraction at which people represent objects and actions.
\end{abstract}

Keywords Construal level $\cdot$ Motivation $\cdot$ Goals $\cdot$ Warmth $\cdot$ Cold

Motivation can influence how people construe their subjective reality. For instance, Princeton and Dartmouth fans who watched a football match between the two teams had very different impressions of the match and interpreted the events on the field in favor of the team they supported (Hastorf and Cantril 1954). Subsequently to this early documented case of motivated perception, myriad research programs demonstrated that current goals, motives, needs, wishes, hopes, worries, and fears can influence which information people attend to and which strategies people use to make sense of the ambiguous world (for overviews, see e.g., Aarts 2012; Fiske 1993, 2010; Gollwitzer and Moskowitz 1996; Kunda 1990; Showers and Cantor 1985).

Most of this research literature on the "motivated tactician" demonstrates that motivations affect the content of people's construal. That is, people tend to see what they want to see. For instance, depending on one's motivation,

Jochim Hansen

jochim.hansen@sbg.ac.at

1 Department of Psychology, University of Salzburg, Hellbrunnerstr. 34, 5020 Salzburg, Austria

2 Cass Business School, City University of London, London, UK one interprets events or objects more negatively or more positively, such as an incident on the football field which can be construed as severe foul or as harmless touch, or a piece of organic fruit which can be viewed as expensive extravagance or as healthy addition to one's diet. We extend previous research by showing that motivations can also affect the level of construal, that is, how concretely versus abstractly people represent their reality. We suggest that motivations cause people to construe stimuli that are relevant to the current motivation on a more concrete level than stimuli that are not relevant, much like in a cartoon in which a very hungry castaway who floats on a raft through the ocean imagines a yummy steak very concretely with all its visual and gustatory details. Specifically, here we investigated the influence of temperature (warmth versus cold) on the construal level of stimuli that could help to reduce the unpleasantness of the temperature.

\section{Motivated perception}

The same object can be interpreted very differently, depending on one's motivation. This effect even happens at a very early stage of perception (Balcetis and Dunning 2010; 
Dunning and Balcetis 2013). For instance, wishes caused participants to interpret an ambiguous figure in a way that fits their goals (Balcetis and Dunning 2006). Moreover, thirsty participants perceived an ambiguous stimulus as more transparent (i.e., water-like) than quenched participants (Changizi and Hall 2001). Such effects can be explained by an activation of goal-relevant associations, which color the interpretation of a given stimulus. For instance, the concept "water" and its associated features-such as transparencymay be more active in thirsty participants than in quenched participants, and may thus be more likely to be applied when interpreting an ambiguous stimulus.

Of interest for the present research, motivations have been shown to influence distance perception (Balcetis 2016; Cole et al. 2013; Stefanucci e al. 2008). Desirable objects are perceived to be closer than neutral objects (Valdés-Conroy et al. 2012). For instance, money appears closer than financially valueless objects (Cole and Balcetis 2013). Thirsty participants estimated a water bottle as being closer than participants who were not thirsty (Balcetis and Dunning 2010). Similarly, a diagnostic survey that provided flattering feedback appeared to be closer than a survey that provided critical feedback (Balcetis and Dunning 2010). The opposite effect has also been shown: Undesirable stimuli appear to be more distant. For instance, distance to the starting point of travel was overestimated by travelers who preferred their destination over their starting point (Alter and Balcetis 2011).

These effects can be explained by different motivational directions elicited from the current situation (i.e., the exposure to an affective object, the situational constraints, and the available resources; Balcetis 2016). When one is motivated to reach a goal or to fulfill a need, one tends to have the drive to approach stimuli that are helpful in reaching the goal or in fulfilling the need. It has been argued that an intense motive, combined with the presence of an object that can satisfy that motive, results in a pronounced approach orientation (Loewenstein 1996). An approach orientation prepares people to act on such stimuli. In this sense, it is functional to represent the stimuli closer because closeness enables mental simulation of adaptive responding to the stimulus, and thus can facilitate adaptive responding. In contrast, motivation to avoid a stimulus leads people to see the respective stimulus as more distal. One rarely acts on stimuli that one wants to avoid, and thus it is psychologically adaptive to represent those stimuli as more distal.

\section{Motivated construal level}

The functional perspective on motivated cognition implies that motivation stimulates any mental representation that helps adaptive responding according to the motivation
(Zhang and Risen 2014). Thereby, motivated cognition is part of successful self-regulation (i.e., the purposeful regulation of actions to reach a goal; Carver and Scheier 2016). Self-regulation can be structured in different phases, ranging from forethought to performance and action, to feedback and self-reflection (Zimmerman 2000). Several operations help to translate intentions to pursue a goal into the attainment of the goal, including affective and behavioral processes, metacognitive knowledge and skills, and a resilient sense of confidence to control one's actions (Bagozzi 1992). Thus, individuals select the means to reach their goals, for instance, by automatically actuating a stored script or by generating novel means. Other self-regulatory operations include judging one's degree of self-efficacy with which relevant actions can be executed, convincing oneself that one is capable of reaching a selected goal (Bandura 1991). The motivationally triggered transformation of cognitions might constitute another mechanism of self-regulation, which stimulates the individual to approach goal-relevant targets. Motivated cognition might be especially effective at the forethought phase of self-regulation, to motivate the individual to approach goal-relevant targets. As part of motivated cognition, as discussed above, people tend to view motivationally relevant stimuli as physically closer.

However, perception of proximity is one option to foster adaptive responding, but not the only one. We argue that concreteness of mental representation (i.e., low-level construal) more broadly allows for preparation of adaptive responding and thereby point out another operation of successful self-regulation. Any event, object, and person can be represented at different levels of construal (Burgoon et al. 2013; Medin and Smith 1984; Rosch 1975, 1978; Semin and Fiedler 1988, 1991; Shapira et al. 2012; Trope and Liberman 2003, 2010; Vallacher and Wegner 1987, 1989). High-level construals include fewer details and less contextual information than low-level construals. More specifically, high-level construals are abstract mental representations that extract the essential, core aspects of an object, person, or event. Moving from a concrete representation to a more abstract representation involves retaining central features and omitting features that may vary without significantly changing the meaning of the represented information. Low-level, concrete construals, in contrast, consist of rich and specific details. Such construals emphasize subordinate (vs. superordinate) features of an object, person, or event, focusing on local (vs. global) perceptual elements, and processing information in a detailed-oriented (vs. holistic) manner (e.g., Shapira et al. 2012; Trope and Liberman 2010).

When preparing for an action, low-level construals may be more functional than high-level construals. For instance, cybernetic theories of action control argue that actions are translated into sub-goals when the time of implementation approaches (Carver and Scheier 1981; Vallacher and Wegner 
1987). When actions come close in time and space, their representation increasingly includes specific means or even specific movements that are executed during the action. In other words, as actions are approached, they are construed on a more concrete level. This is the case because concrete, lowlevel construal promotes adaptive responding. For instance, it has been demonstrated that a concrete, specific construal of goals (e.g., "try to reach 74 correct responses on this task within the next 20 min") are more motivating and lead to better performance than more abstract, vague construal of goals (e.g., "try your best on this task") (Latham and Locke 1991; Locke et al. 1989; Locke and Latham 1990; for metaanalyses, see; Mento et al. 1987; Tubbs 1986). Likewise, a concrete construal of actions (in form of implementation intentions, i.e. "If I encounter Situation X, then I'll perform Behavior Y!") triggers automatic action initiation (e.g., Gollwitzer 1993, 1999); and individuals are more ready to imitate behavior thoroughly when construing a model concretely (vs. abstractly; Hansen et al. 2016). Finally, research on self-control has shown that individuals pursue short-term goals that map on their current, situated motivation (e.g., experiencing the yummy taste of a donut in one's mouth) more than distant long-term goals (e.g., following a diet) when thinking concretely than when thinking abstractly (Fujita et al. 2006). Together, these lines of research suggest that a concrete construal is more situationally bounded and enables adaptive responding to urgent motivations in the here-and-now.

Conversely, concreteness of a goal can increase one's motivation (Kivetz et al. 2006). For example, people are more motivated to help a concrete identifiable person than a more abstract group of people (Kogut and Ritov 2005). Given the close relation between concreteness and motivation, it seems to be adaptive to construe actions more concretely when they are about to be executed.

Identifying a novel path by which concreteness and motivation might be linked, we propose that not only are concrete stimuli more motivating, but people might actively construe any stimulus (i.e., any object or person) on a more concrete level when that stimulus is appropriate to fulfill one's goals and thus is motivationally relevant. On the one hand, this should be the case because goal-relevant stimuli are mentally closer than stimuli that are relevant to an alternative motivational state. For instance, a cold drink is relevant to a person when s/he feels warm, whereas a warm drink is relevant to the person when s/he is in an alternative, hypothetical motivational state (feeling cold). Since objects relevant to an actual state are psychologically closer than objects related to a hypothetical state, the former objects should be construed more concretely than the latter, according to construal level theory (Trope and Liberman 2003, 2010). Therefore a cold drink should be construed more concretely than a warm drink when one is feeling warm. On the other hand, adaptive responding to a motivationally relevant object may generally be easier when the object is already construed on a low level. This is the case because stimuli that are construed on a low level are represented in more detail and comprise more contextual information, which facilitates adaptive responding.

\section{The present research}

We argue that - much as motivated distance perception may assist in prompting adaptive action (Cole et al. 2014) motivated level of construal may be a previously unknown mechanism to serve the same function. The present research tested the idea that motivational states affect the level of construal of stimuli that are relevant to the person in that state. In three experiments, we used temperature (warmth versus cold) to manipulate motivational states, by manipulating actual room temperature or by using mental simulations of warmth versus cold. We tested the hypothesis that warmth causes participants to construe stimuli that could potentially help to reduce the warmth more concretely than stimuli that could not. In contrast, cold would cause participants to construe stimuli that could help to reduce the cold more concretely than stimuli that could not. To measure level of construal, we used breadth of categorization of motivationally relevant (vs. irrelevant) objects (Exp. 1), level of identification of motivationally relevant (vs. irrelevant) actions (Exp. 2), and weighting of aggregated versus individualized information when evaluating motivationally relevant (vs. irrelevant) products (Exp. 3).

In all experiments, we explain how the sample size was determined. All measures and manipulations are reported, and all exclusions are explained. For all materials and data, see https://tinyurl.com/motivated-construal.

\section{Experiment 1: Category breadth}

We tested the hypothesis that experiencing warmth causes participants to construe objects related to cold (warmth) on a lower (higher) level than experiencing cold. Since previous research has shown that cold (versus hot) beverages are more desirable when experiencing warmth (versus cold; Steinmetz et al. 2018), we used hot versus cold beverages as stimulus objects. Participants were seated in either a warm or a cold room and asked to classify diverse hot or cold beverages into as many categories as they deemed appropriate. When objects are represented concretely, people use more and narrower categories (Liberman et al. 2002). Accordingly, we expected that participants in a cold (versus warm) room would use more and narrower categories of hot beverages. Likewise, we expected that participants in a warm (versus 
cold) room would use more and narrower categories of cold beverages.

\section{Method}

\section{Participants and design}

One-hundred and forty-five students of a German university took part in the study. They were randomly assigned to a 2 (Room temperature: cold, warm) $\times 2$ (Type of beverages: cold, hot) between-participants design. We excluded nine participants because they reported that they felt disturbed during the experiment either because of loud noises stemming from the heating/cooling system $(n=4)$, strong time pressure $(n=4)$, or hunger $(n=1) .{ }^{1}$ The remaining sample consisted of 136 participants ( 96 females, 40 males). Age ranged from 18 to 45 years $(M=24.3, S D=4.3, M d n=24)$. We determined the sample size based on effects sizes found in related research: For instance, Balcetis and Dunning 2010 (Exp. 1) found an effect of $d=0.43$ (which translates to $f=0.215$ ), Cole et al. (2014, Exp. 1) found an effect of $d=0.50$ (which translates to $f=0.25$ ), and Zhang and Risen (2014, Exp. 1) found an effect of $\eta^{2}=0.09$ (which translates to $f=0.315$ ). Entering the average of these three effect sizes $(f=0.26)$ and a desired power of $1-\beta=0.80$, an alpha level of $\alpha=0.05$ into the program G*Power (Faul et al. 2009) with specifying the numerator $d f=1$ and number of groups $=4$ resulted in a total sample size of 119 , which means at least 30 participants per experimental condition.

\section{Materials and procedure}

Following a procedure by IJzerman and Semin (2009; see also Steinmetz and Mussweiler 2011), participants were seated either in a cold room (approx. $17-18^{\circ} \mathrm{C}$ ) or a warm room (approx. $24-25{ }^{\circ} \mathrm{C}$ ) to induce feelings of cold and warmth, respectively. A thermometer was placed in each room, outside of the visibility of the participants, to constantly monitor the lab temperature. New participants were only brought into the lab room when the appropriate temperature was reached. Participants first worked on an unrelated filler task for about 5 min to allow the room temperature to unfold its impact (similar to Steinmetz and Mussweiler 2011). Next, participants were presented with a list of 30 beverages (written one below the other on the left side of a piece of paper). For half the participants, the list consisted of cold beverages (e.g., apple juice, coke, ice tea,

\footnotetext{
1 The predicted interaction effect was no longer statistically significant when including these participants in the analysis, $F(1,141)=$ $2.35, p=.128, \eta_{\mathrm{p}}^{2}=.02$.
}

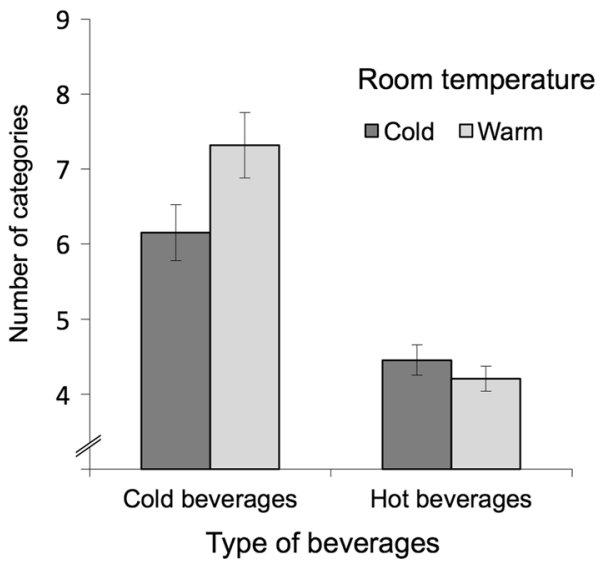

Fig. 1 Mean number of categories for beverages as a function of room temperature and type of beverages $( \pm 1 S E)$

wheat beer, orange juice, mineral water); for the other half of participants, the list consisted of hot beverages (e.g., hot milk with honey, cappuccino, herbal tea, hot lemon juice, black coffee). Participants were asked to place the items that belonged together into groups by copying them on the right side of the list and circling the group. They were instructed to classify every item into non-overlapping groups. Such a categorization task has been used previously to measure abstraction (e.g., Isen and Daubman 1984; Lee and Ariely 2006; Liberman et al. 2002). Additionally, we asked participants whether they had comments on the study in a free response format. As mentioned above, nine participants were excluded from the analyses because they reported at this point that they had felt disturbed during the study.

\section{Results and discussion}

The number of categories was analyzed with a 2 (Room temperature) by 2 (Type of beverages) analysis of variance (ANOVA), with both factors between-participants. Cold beverages were classified into more categories $(M=6.74$, $S D=2.44)$ than hot beverages $(M=4.33, S D=1.96)$, $F(1,132)=56.50, p<.001, \eta_{\mathrm{p}}{ }^{2}=0.30,90 \%$ CI [0.195; $0.393]$. This main effect was qualified by a significant interaction between room temperature and type of beverages, $F(1,132)=4.91, p=.028, \eta_{\mathrm{p}}{ }^{2}=0.04,90 \%$ CI $[0.002 ; 0.101]$. As hypothesized and as can be seen in Fig. 1, room temperature had an effect on category breadth of cold beverages. Participants in the warm room classified the cold beverages into more (and smaller) categories $(M=7.31, S D=2.60)$ than participants in the cold room $(M=6.15, S D=2.16)$, $F(1,132)=6.78, p=.010, \eta_{\mathrm{p}}{ }^{2}=0.05,90 \%$ CI $[0.006 ; 0.120]$, for the contrast, indicating that cold beverages were construed on a more concrete, low level when sitting a warm 
(vs. cold) room. However, in contrast to our hypothesis, room temperature did not affect category breadth of the hot beverages $\left(M_{\text {warm room }}=4.21, S D=0.98 ; M_{\text {cold room }}=4.45\right.$, $S D=1.15), F(1,132)=0.30, p=.586, \eta_{\mathrm{p}}{ }^{2}=0.002,90 \% \mathrm{CI}$ $[0.000 ; 0.034]$. The main effect of room temperature was not significant, $F(1,132)=2.07, p=.153, \eta_{\mathrm{p}}{ }^{2}=0.02,90 \% \mathrm{CI}$ [0.000; 0.066].

The findings of Experiment 1 provide first support for the hypothesis that motivation affects level of construal. Participants in a warm room construed stimuli that could help to reduce the warmth (i.e., cold beverages) on a more concrete level than participants in a cold room. However, so far the support for our hypothesis is only tentative at most: First, the effect disappeared when including participants who felt distracted during the study (see Footnote 1). Second, we found the effect only for cold beverages but not for warm beverages. The latter finding is probably due to an a priori smaller variety of hot beverages on the list since the list consisted mainly of different teas, hot milk drinks, and types of coffee drinks. The list of cold beverages was much more heterogeneous, in contrast, as reflected in larger standard deviations and participants' classification into more categories overall. Additionally, if the ambient outside temperature was generally colder than the temperature in the lab, the decrease in temperature for the cold condition might not have been as salient as the increase in room temperature in the warm condition, resulting in a stronger effect in participants brought into a warm room. Given the problems with the present study and the materials, we used different measures for level of construal in Experiments 2 and 3.

\section{Experiment 2: Action identification}

In Experiment 2, we used a different temperature manipulation to avoid the noise disturbance problems caused by the heating and cooling system in Experiment 1. More specifically, temperature was primed with short movies, which showed either a desert or a winter-scenery. Participants were asked to imagine themselves in the situation as best as they could. Such a procedure has been shown to activate the concepts of warmth and cold, respectively, and to shift people's behavior and preferences accordingly (Halali et al. 2017; Steinmetz and Posten 2017). More specifically, simulating being in a warm versus cold environment makes people actually experience physical warmth and cold, respectively similarly to actual experiences, which is why people's preferences and behavior are affected by the simulations (Steinmetz et al. 2018). Subsequently, participants were presented with a list of actions that were related to cold, to warmth, or that were motivationally neutral. Following the format of the behavioral identification form (BIF, Vallacher and Wegner 1989) that measures the abstractness level on which actions are identified, we presented participants with two alternative descriptions of the actions (one more concrete and one more abstract) and asked participants to choose which of the two best represented the given action. We proposed that the level of action identification of participants primed with the desert movie would be higher (i.e., more abstract) for the warm than for the cold items whereas the level of action identification of participants primed with the winter movie would be higher (i.e., more abstract) for the cold than for the warm items.

\section{Method}

\section{Participants and design}

One-hundred students of a German university (75 females, 21 males, 4 unreported) took part in a study that ostensibly dealt with evaluation of videos. Age ranged from 18 to 60 years $(M=23.4, S D=6.9, M d n=21)$. Participants were randomly assigned to a 2 (Movie: desert, winter-scenery) $\times 3$ (Type of actions: cold, hot, neutral) split-plot design with the first factor varied between participants and the second factor varied within participants. As in Experiment 1, we determined the required sample size based the average effect size found in the related literature (Balcetis and Dunning 2010; Cole et al. 2014; Zhang and Risen 2014). Entering the effect of $f=0.26$ and a desired power of $1-\beta=0.80$, an alpha level of $\alpha=0.05$ into the program $G^{*}$ Power (Faul et al. 2009) with specifying the number of groups with 2 and the number of measurements with 3 , with an assumed correlation between the repeated measures of $r=0$, resulted in a total sample size of 50, which means at least 25 participants per experimental condition. However, by mere luck, data collection went faster than expected and we were able to double the number of participants (i.e., 50/cell) and thus to increase power. No data were excluded from analyses.

\section{Materials and procedure}

Participants were informed that they would watch a short movie clip and were instructed to imagine themselves in the depicted situation as best as possible. Specifically, they were asked to imagine being a person in the scene and to visualize the scene with all feelings and needs that may be experienced in the situation depicted in the movie. Participants watched a movie clip that lasted approximately $90 \mathrm{~s}$. For half of the participants, the movie clip depicted a winter landscape with a lot of snow, accompanied by sounds of cold winds. For the other half of participants, the clip depicted a desert landscape with a lot of hot sand, accompanied by chirr sounds. After watching the clip, participants rated how good $(1=$ very bad, $7=$ very good $)$ and how pleasant $(1=$ very 
unpleasant, $7=$ very pleasant) they found the movie clip to be. Additionally, they indicated how well they were able to imagine themselves in the scenery $(1=$ very poorly, $7=$ very well).

After the temperature priming task, participants worked on an adapted version of the BIF (Vallacher and Wegner 1989). Participants were provided with 24 actions (e.g., recycling) and two alternative descriptions of each action. One of the alternatives always offered a description that emphasized the concrete means by which the action is performed (e.g., bagging paper, glass, and cans). The other alternative was always more abstract and emphasized the end for which the action is performed (e.g., caring for the environment). For each action, participants were asked to choose the description that expressed the action better than the other. Importantly, 8 actions were related to warmth (e.g., sitting at the fire, having a sauna, using a hot-water bottle, running through hot sand), 8 were related to cold (e.g., drinking cold water, walking through cold rain, hiking in the snow, making ice cubes), and 8 items were neutral (e.g., skydiving, making an expensive purchase, recycling, teaching; see Fujita et al. 2006, Exp. 3a). By including the neutral items, we can test whether our effects are specific to motivationally relevant items. The order of the 24 items and the order of the two response options were completely randomized. The number of abstract choices of the warmth items, the cold items, and the neutral items served as the measures of abstract construal of actions related to warmth, actions related to cold, and actions unrelated to temperature, respectively.

\section{Results and discussion}

The number of abstract choices were analyzed with a 2 (Movie) by 3 (Type of actions) ANOVA with the second factor being within-participants. This analysis revealed a main effect of type of actions, $F(2,196)=33.08, p<.001$, $\eta_{\mathrm{p}}{ }^{2}=0.25,90 \%$ CI $[0.165 ; 0.328]$. Participants chose fewer abstract descriptions for the neutral items $(M=4.25$, $S D=1.34)$ than for the heat items $(M=5.56, S D=1.70)$, $F(1,98)=39.23, p<.001, \eta_{\mathrm{p}}{ }^{2}=0.29,90 \%$ CI [0.165; 0.393], and the cold items $(M=5.84, S D=1.61), F(1,98)=59.78$, $p<.001, \eta_{\mathrm{p}}{ }^{2}=0.38,90 \%$ CI $[0.254 ; 0.480]$. Heat and cold items did not differ, $F(1,98)=1.64, p=.203, \eta_{\mathrm{p}}{ }^{2}=0.02,90 \%$ CI $[0.000 ; 0.079]$. We refrain from interpreting the main effect between the temperature items and the neutral items since the items differed strongly in content, additionally to the temperature connotation. The main effect of the movie was not significant, $F(1,98)=0.07, p=.792, \eta_{\mathrm{p}}{ }^{2}=0.001$, $90 \%$ CI [0.000; 0.028].

Importantly, as hypothesized and can be seen in Fig. 2, the movie interacted with the type of actions, $F(2,196)=3.14, p=.045, \eta_{\mathrm{p}}{ }^{2}=0.03,90 \%$ CI $[0.000$;

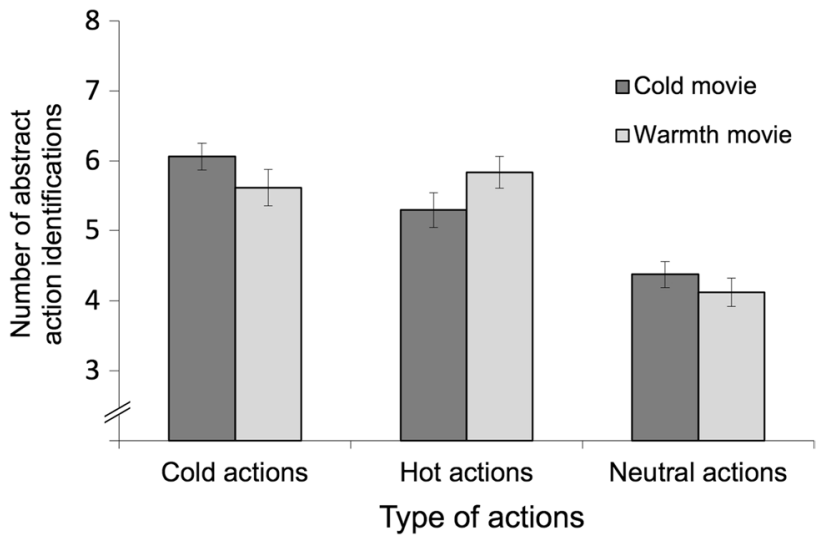

Fig. 2 Mean number of abstract choices as a function of type of movie and type of actions $( \pm 1 S E)$

0.075]. Depending on the temperature content of the movie, participants chose different numbers of high-level action descriptions of the heat and cold items: Participants who watched the cold movie chose more abstract descriptions for the cold items $(M=6.06, S D=1.36)$ than participants who watched the warm movie $(M=5.61, S D=1.82)$, whereas participants who watched the warm movie chose more abstract descriptions for the heat items $(M=5.84$, $S D=1.60)$ than participants who watched the cold movie $(M=5.29, S D=1.76), F(1,98)=5.50, p=.021, \eta_{\mathrm{p}}{ }^{2}=0.05$, $90 \%$ CI [0.004; 0.138] for the interaction contrast.

The findings of Experiment 2 provide further support for the hypothesis that motivation affects level of construal. Participants who envisioned themselves in a desert construed actions that could help to reduce the (presumably) experienced warmth on a more concrete level than participants who envisioned themselves in a winter-scenery. In contrast, participants who envisioned themselves in a winter-scenery construed actions that could help to reduce the (presumably) experienced cold on a more concrete level than participants who envisioned themselves in a desert. In contrast, the temperature manipulation did not affect the construal of the neutral items. Thereby, the hypothesis that temperature influences people's construal of motivationally relevant items, but not of irrelevant items, is supported.

However, the findings show that motivation affected construal level more in the cold movie condition than in the warmth movie condition. This difference could be explained by the fact that the cold movie was filmed from a first-person perspective, whereas the warmth movie was filmed from a third-person perspective. Accordingly, it was possibly easier to follow the instructions to imagine oneself in the environment for the cold movie condition than for the warmth movie condition, which may have resulted in the stronger effect in the cold 
movie condition. In Experiment 3, we used a different method to manipulate cold versus warmth to avoid possible confounds.

Additionally, there was some conceptual similarity between the content of the temperature primes (e.g., the depiction of snow), and some of the temperature-related items (e.g., hiking in the snow). Such similarity could potentially introduce a confound by activating the concept of snow and thereby increasing participants' likelihood to choose the snow-related action (regardless of whether snow was part of the concrete or abstract representation). To address this confound, we took great care to use a variety of temperature-related items (e.g., ice cubes, etc.) to minimize the conceptual overlap between the primes and the items. Nevertheless, if this confound affected participants' judgments, the expected pattern of results would be different from what we found. Specifically, participants who watched the snow video would be more likely to select all snow-related options, regardless of their level of abstraction. However, we found that participants who watched the snow video chose more abstract representations of cold-related items across the specific content of these items.

\section{Experiment 3: Weighting of individualized versus aggregated information}

Research has shown that level of construal influences the type of information on which participants base their judgments and decisions. That is, when construing an object on a low level, people shift their attention from aggregated to individualized information about the object (Bruchmann and Evans 2013; Ledgerwood et al. 2010). For instance, low-level, concrete representations enhance the relative influence of product information that is closely tied to a single experience within a specific context compared to broad, decontextualized information which is averaged across multiple individuals and instances (Ledgerwood et al. 2010). In Experiment 3, we investigated whether such a downstream consequence of level of construal is affected by motivational states. Specifically, we tested the hypothesis that warmth would cause participants to put more weight on individualized information than on averaged information when the evaluated object could help to reduce the warmth, that is, when participants evaluate ventilators. Cold, in contrast, should cause participants to put more weight on individualized information than on averaged information when the evaluated object could help reducing the cold, that is, when participants evaluate heaters.

\section{Method}

\section{Participants and design}

Sixty students of an Austrian university (41 females, 19 males) took part in a study that ostensibly dealt with perspective-taking skills. Age ranged from 16 to 62 years $(M=23.4, S D=7.7, M d n=21)$. Participants were randomly assigned to a 2 (Prime: warm, cold) $\times 2$ (Product: ventilators, heaters) $\times 2$ (Information Type: product favored by average information, product favored by individualized information) mixed design with the second and third factors varied within participants. As in Experiment 1, we determined the required sample size based the average effect size found in the related literature (Balcetis and Dunning 2010; Cole et al. 2014; Zhang and Risen 2014). Entering the effect of $f=0.26$ and a desired power of $1-\beta=0.80$, an alpha level of $\alpha=0.05$ into the program G*Power (Faul et al. 2009) with specifying the number of groups with 2 and the number of measurements with 4 (since participants rated heaters and ventilators favored by individualized information and heaters and ventilators favored averaged information), with an assumed correlation between the ratings of $r=0$, resulted in a total sample size of 42 , which means at least 21 participants per experimental condition. Again, we were lucky to be able to run more participants (i.e., 30 per cell) and to thus increase power. No data were excluded from analyses.

\section{Materials and procedure}

Participants were instructed to read a short story and to try to take the perspective of the protagonist and relive his/her feelings and thoughts as best as they could. Participants read a story about a person who was waiting for the bus either on a very hot summer day or on a very cold winter day (between participants). Both stories were written from a first-person perspective. As in Experiment 2, we expected that the simulation of the stories would lead people to actually feel warmer versus colder (building on Steinmetz et al. 2018), which would subsequently affect their judgments. Specifically, the stories read:

It is hot [cold]. In the morning, the thermometer has already shown $31{ }^{\circ} \mathrm{C}\left[-13{ }^{\circ} \mathrm{C}\right]$, and also during the previous days, the temperature was well above $30^{\circ}$ [below $0^{\circ}$ ]. I'm standing at the bus stop in the hope of catching the last bus. My sweat flows [I get goose bumps] when I think about walking by foot for $1 \mathrm{~h}$ in the boiling heat [in the bone-chilling cold] under the blazing sun [through snowfall and without gloves]. But thank god the bus is turning around the corner, and I'm looking forward to entering the air-conditioned [heated] bus and to escaping the torrid heat [the biting cold]. But when the doors open, hot [cold] air streams against me. Unfortunately, I had to find out that the airconditioning [the heating unit] of the bus is not working. I have the feeling that it is even hotter [colder] inside the bus than outside. I start to sweat [to jitter] even more, so much that the sweat is flowing from my 
forehead like water [that my teeth clatter repeatedly and uncontrollably]. After I get off the bus, someone approaches me and asks me to fill in a short questionnaire. $^{2}$

Next, participants were instructed to evaluate the following products as if they were the protagonist. They were asked to imagine purchasing the products via Amazon.com (see Hansen and Melzner 2014; Ledgerwood et al. 2010, for a similar measurement of construal level). They were presented with the pictures of two ventilators on one page and with the pictures of two heaters on another page. The order of the two pages was counter-balanced. Beneath each product, participants found an aggregated evaluation and a single review. One of the ventilators and one of the heaters was favored by the aggregated (abstract) information: They had an average rating of 4.5 out of 5 stars, although the single (concrete) review stated the opposite, namely that "the ventilator has no cooling effect and the money should better be invested in a better product" and "the heater is cheap crap and one should better look for an alternative," respectively. The other ventilator and heater were favored by individualized (concrete) information: It had an average (abstract) rating of only 2.5 of 5 stars, but the single review said that "the ventilator is small, very quiet, light, and odorless with a very good cooling effect" and that "the heater has a very good value for money and holds what it promises", respectively. The order of the pictures and the assignment of the information to the pictures were counterbalanced across conditions.

Finally, participants rated how interested, likely, confident, and happy they would be about buying each product and how they generally felt about each product from 1 (not at all/very unlikely/very negative) to 7 (extremely/very likely/very positive). Responses to these five items were averaged for each product to form evaluation scores for the ventilator favored by the aggregated information $(\alpha=0.94)$, the ventilator favored by the individualized information $(\alpha=0.94)$, the heater favored by the aggregated information $(\alpha=0.94)$, and the heater favored by the individualized information $(\alpha=0.95)$.

\footnotetext{
${ }^{2}$ A pretest indicated that these stories effectively influence subjective states. Eighty-five students (59 females, 25 males, 1 unreported) who attended a lecture read the stories and estimated the room temperature of the lecture hall and indicated how strongly they were sweating and how thirsty they were on 7-point scales (among other filler items). Participants who read the warmth story estimated the room temperature to be higher $\left(M=20.6{ }^{\circ} \mathrm{C}, S D=3.3\right)$ than participants who read the cold story $\left(M=17.4^{\circ} \mathrm{C}, S D=7.4\right), t(83)=2.585, p=.011, \eta^{2}=$ .07. Participants who read the warmth story also indicated that they were sweating more $(M=4.07, S D=1.16)$ and were thirstier $(M=$ $4.65, S D=1.69)$ than participants who read the cold story $\left(M_{\text {sweating }}\right.$ $\left.=3.48, S D=1.35 ; M_{\text {thirst }}=3.95, S D=1.61\right), t(83)=2.176, \mathrm{p}=$ $.032, \eta^{2}=.05$ and $t(83)=1.953, p=.054, \eta^{2}=.04$, respectively.
}

\section{Results and discussion}

A 2 (Prime) by 2 (Product) by 2 (Information Type) mixeddesign ANOVA on the evaluation revealed a main effect of the product, $F(1,56)=9.41, p=.003, \eta_{p}{ }^{2}=0.14,90 \%$ CI $[0.030 ; 0.282]$, indicating that participants preferred ventilators $(M=4.02, S D=0.83)$ over heaters $(M=3.59$, $S D=1.07)$. Across products, participants preferred products with the positive individualized information $(M=4.61$, $S D=1.13)$ over products with the positive aggregated information $(M=3.01, S D=1.21), F(1,56)=38.89, p<.001$, $\eta_{\mathrm{p}}{ }^{2}=0.41,90 \%$ CI [0.242;0.532]. Additionally, as could be expected when temperature causes an approach motivation towards objects which could help to fulfill one's needs, the prime interacted with the product, $F(1,56)=25.53$, $p<.001, \eta_{\mathrm{p}}{ }^{2}=0.31,90 \%$ CI $[0.151 ; 0.448]$. Participants who were primed with warmth evaluated the ventilators $(M=4.49, S D=0.64)$ more positively than the heaters $(M=3.23, S D=1.18), F(1,56)=31.87, p<.001, \eta_{\mathrm{p}}{ }^{2}=0.36$, $90 \%$ CI [0.196; 0.492]. In contrast, participants who were primed with cold evaluated the heaters $(M=3.93, S D=0.83)$ more positively than the ventilators $(M=3.62, S D=0.77)$, although the latter difference did not reach significance, $F(1,56)=2.04, p=.159, \eta_{\mathrm{p}}{ }^{2}=0.04,90 \%$ CI [0.000; 0.141].

Importantly, as hypothesized, the effect of prime on evaluations was qualified by the type of information, indicating that participants focused more on the low-level, concrete information when evaluating products that could help reducing the uncomfortable state than when evaluating products that could not, $F(1,56)=10.34, p=.002, \eta_{\mathrm{p}}{ }^{2}=0.16$, $90 \%$ CI $[0.037 ; 0.295]$ for the three-way interaction. As can be seen in Fig. 3, when participants were primed with warmth, they evaluated the concrete version of the ventilator (i.e., favored by individualized information) more positively $(M=5.44, S D=1.35)$ than the abstract version of the ventilator (i.e., favored by aggregated information) $(M=3.55, S D=1.50), F(1,56)=14.17, p<.001, \eta_{\mathrm{p}}{ }^{2}=0.20$, $90 \%$ CI $[0.065 ; 0.342]$ for the contrast. This effect was much smaller for the evaluation of the heaters $\left(M_{\text {individualized }}\right.$ $=3.73, S D=1.50$ versus $\left.M_{\text {aggregated }}=2.72, S D=1.47\right)$, $F(1,56)=5.54, p=.022, \eta_{\mathrm{p}}{ }^{2}=0.09,90 \%$ CI $[0.007 ; 0.219]$ for the contrast; $F(1,27)=4.84, p=.037, \eta_{\mathrm{p}}{ }^{2}=0.15,90 \% \mathrm{CI}$ $[0.005 ; 0.344]$ for the interaction within the warmth-primed group (Fig. 3, Panel A). In contrast, when participants were primed with cold, they evaluated the concrete version of the heater (i.e., favored by individualized information) more positively $(M=5.23, S D=1.51)$ than the abstract version of the heater (i.e., favored by aggregate information) $(M=2.63, S D=1.61), F(1,56)=39.35, p<.001, \eta_{\mathrm{p}}{ }^{2}=0.41$, $90 \%$ CI $[0.245 ; 0.535]$ for the contrast. This effect was only marginally significant for the evaluation of the ventilators, $\left(M_{\text {individualized }}=4.10, S D=1.55\right.$ versus $M_{\text {aggregated }}=3.14$, 

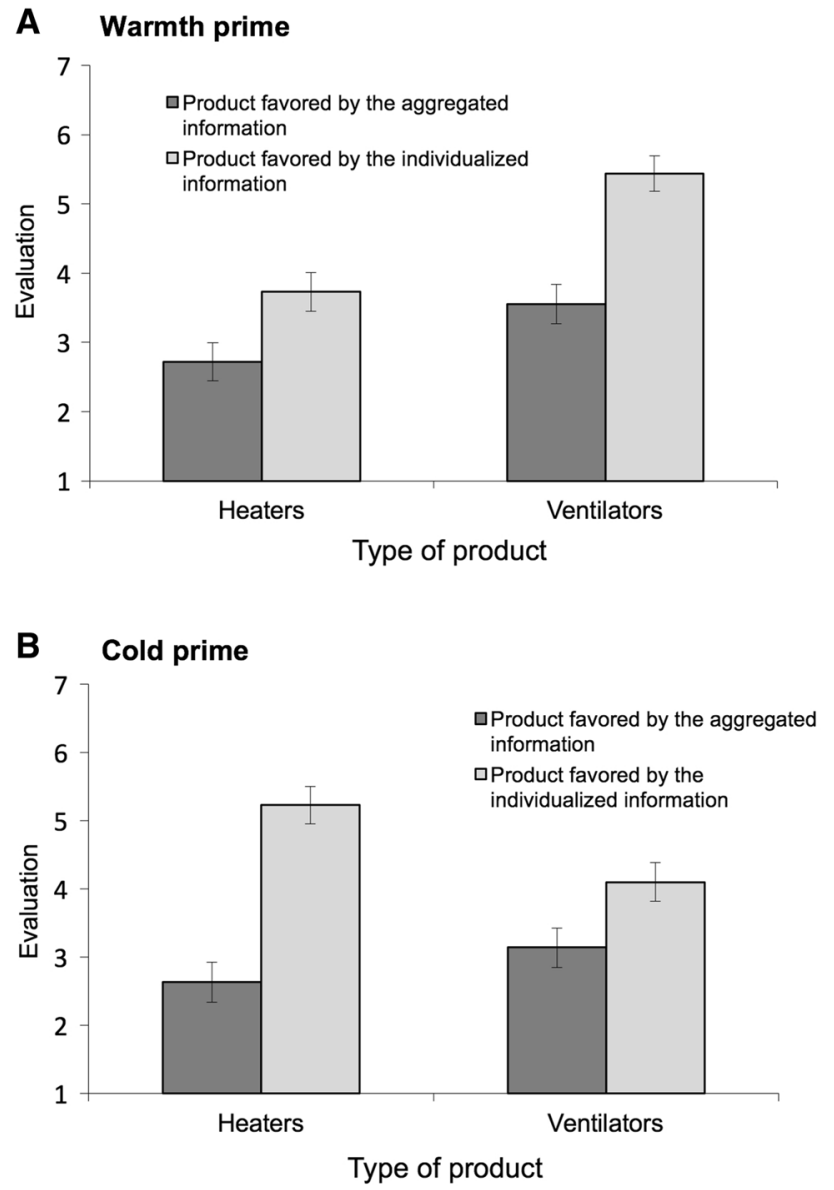

Fig. 3 Mean evaluations of heaters and ventilators as a function of type of information which favored the product (aggregated or individualized) and prime (warmth versus cold) $( \pm 1 \mathrm{SE})$

$S D=1.59), F(1,56)=3.94, p=.052, \eta_{\mathrm{p}}{ }^{2}=0.07,90 \% \mathrm{CI}$ [0.000; 0.187] for the contrast; $F(1,29)=6.20, p=.019$, $\eta_{\mathrm{p}}{ }^{2}=0.18,90 \%$ CI $[0.017 ; 0.363]$ for the interaction within the cold-primed group (Fig. 3, Panel B). The interaction between prime and information type, $F(1,56)=0.41$, $p=.525, \eta_{\mathrm{p}}{ }^{2}=0.01,90 \% \mathrm{CI}[0.000 ; 0.081]$, and the interaction between product and information type, $F(1,56)=0.93$, $p=.338, \eta_{\mathrm{p}}{ }^{2}=0.02,90 \%$ CI $[0.000 ; 0.105]$, were not significant.

Taken together, the warmth (vs. cold) prime lead participants to evaluate the coolers (vs. heaters) more positively, consistent with previous research on goal activation (Zhang and Risen 2014). Our results additionally show that this effect is moderated by the information on which participants focus. Whereas more concrete information in our experiment generally has a larger influence on evaluations, this effect is even more pronounced for those products that are goal-relevant (i.e., coolers in the warm condition and heaters in the cold condition), because participants focus on concrete information especially when that information is goal-relevant. As an alternative explanation, one might argue that the findings of Experiment 3 are not mainly driven by the fact that the information is provided in abstract or concrete terms per se, but by the fact that the individualized information already evokes goal attainment. In other words, when a goal is activated, people might rely more on information that promises goal attainment than information that does not, without necessarily considering the construal level on which the information is conveyed. However, in our view, the averaged information in form of many versus few stars is just as useful for goal attainment (i.e., receiving information of the product) as the individual information, which renders this alternative explanation rather unlikely.

\section{General discussion}

The findings of the present research generally support the idea that motivational states can affect level of construal. Experiment 1 provided evidence for the hypothesis that participants who experienced warmth were construing cool beverages more concretely than participants who experienced cold. Experiment 2 extended these findings by demonstrating that participants who imagined themselves in a hot environment were construing actions related to cold more concretely than actions related to heat, whereas the reverse was found for participants who imagined themselves in a cold environment. Finally, Experiment 3 showed a downstream consequence of the motivated-construal effect: Motivation affected the type of information on which participants based the evaluation of products. When evaluating products that potentially match one's current motivation (e.g., reducing experienced warmth or cold), participants placed more weight on concrete, individualized product features than on abstract, averaged product features-more so than when evaluating products that did not match their current motivational state.

We suggest that a concrete construal of actions and objects that may help to reach one's goals or to fulfill one's needs is psychologically adaptive because concrete construal may better enable mental simulation of adaptive responding to the stimulus. Such a functional view of motivated construal fits previous research that shows that concretely construed events seem more likely to happen (Wakslak and Trope 2009) and that a concrete construal supports a focus on the effects of actions instead of the causes (Hansen et al. 2013; Rim et al. 2013). Both consequences of concrete construal-increased likelihood perceptions and a focus on effects of actions-may guide motivation and provide a cognitive mechanism that supports motivated action.

We argue that experiencing a visceral state, such as cold or warmth, can motivate participants to reduce that state (see also Zhang and Risen 2014), and thus causes concrete 
construal of actions and objects that help to reduce the state. Yet, one may wonder whether the temperature primes actually led participants to feel warmer versus colder, and whether this visceral state prompted the motivation to seek goal-relevant objects or activities. We believe so, as previous literature (e.g., Steinmetz et al. 2018) has demonstrated that even looking at pictures of warm or cold environments can increase feelings of warmth or cold, respectively. Additionally, the findings of the pretest in Experiment 3 (see Footnote 2) suggest that the primes effectively altered the states of the participants. Following from this notion, we would expect that satisfying the motivational state would also eliminate the effects of the primes on level of construal. For instance, offering a cold drink to participants who were primed with warmth would cause participants to not any longer represent further cold drinks on a more concrete level. Future research is needed to test this hypothesis.

As an alternative, non-motivational account of the present findings, one could argue that any visceral state per se, such as warmth, would foster an abstract construal of actions and objects which are related to that state (e.g., warm beverages), instead of increasing concrete construal of actions and objects related to the opposite, pursued state (e.g., cold drinks). Previous research on construal level theory (Trope and Liberman 2003, 2010), however, speaks against such an interpretation of our data, as it convincingly demonstrated that the present is construed more concretely than the future. Accordingly, a present visceral state (and its related concepts) should be construed more concretely than its solution (which lies in the future). Thus, according to construal level theory, when experiencing warmth, participants should represent actions and objects related to this present state as more concrete (and not as more abstract). Nevertheless, even if it was the case that actions and objects that are related to the current state are construed on an abstract, generalized level, it may still be possible that such a generalized view of the current motivational state helps to build up motivation: An abstract construal of the current state may show that it is of primary concern and may urge the individual towards its solution. Such a process does not prohibit a concrete representation of then approached stimuli. Both processes may be two sides of the same coin and act in tandem to foster adaptive responding.

Relatedly, it may be that participants felt an avoidance motivation toward the objects that would exacerbate their current aversive state. For example, if one is warm, a warm beverage may elicit an avoidance motivation. One could argue that this motivation, in turn, may lead to a more concrete construal of the warm beverage. Apart from the fact that a warm feeling may just as well lead to an approach motivation (towards cold drinks), such an effect would not be in line with the present findings and, at best, may be an opposing force that works against the found effect, which may explain the fact that some of the present findings are mixed (see e.g., Footnote 1). Additionally, while it has indeed been demonstrated that an avoidance motivation causes more concrete thinking it general (Friedman and Förster 2001; Lee et al. 2010), it has not been shown that specific objects are construed more concretely. In this respect, the present findings suggest that motivational relevance is a moderator of the general finding that avoidance motivation causes concrete construal.

While the discussion in the previous paragraph focuses on "content-free" construal processes (i.e., both warmth and cold may lead to concrete versus abstract construal), it is also possible that one specific state (e.g., warmth) directionally triggers a specific construal level (e.g., concrete construal). Indeed, it has been argued that warmth fosters concrete construal per se (IJzerman et al. 2014; IJzerman and Semin 2009). That account would suggest a main effect: Warmth should generally lead to more concrete construal of all stimuli. Although such a main effect was not visible in our data, it may explain part of the present data: For instance, it would explain why we did not find a full cross-over interaction in Experiment 1 (i.e., why participants in a warm room represented hot beverages as concrete as cold beverages). However, a potentially confounding main effect of temperature cannot explain the interaction effects found in the present research, by which warmth affects only goal-relevant stimuli but not all stimuli.

One limitation of the present findings is that, in Experiments 1 and 2, the effect of interest was present either only for warmth (Exp. 1) or only for cold (Exp. 2), respectively. Merely in Experiment 3, the warm and the cold motivational states both shifted level of construal. This disparity may be due to the differences in the novel experimental paradigms that were used. Thus, each experiment might have its unique weaknesses, as discussed in the Discussion sections of the single experiments. Importantly, however, the interaction effect emerged in all experiments, which corroborates our main hypothesis across experiments. Even if the evidence of a single experiment was not as reliable as one would have wished, the overall pattern of findings strongly supports the idea that individuals construe goal-relevant stimuli more concretely than goal-irrelevant stimuli.

Additionally, the critical reader might be concerned that our results stem from compliance with perceived experimental demand. However, the nature of our dependent variables renders such an explanation unlikely. Especially in Experiment 3 , although the effect of temperature on the evaluation of the two product types (i.e., warmth causes a preference for ventilators; cold causes a preference for heaters) may be explained by demand characteristics, the effect of interest cannot. To be able to give presumably desirable answers, participants would have to intuit that we expect temperature to affect motivation and thereby construal and that we expect 
these construal differences to result in differences in attention to the more global versus more individual evaluations of different products of the same category - a reasoning that is likely beyond the scope of psychological sophistication that most participants have. Thus, we expect that experimental demand cannot explain our results as a whole.

Our findings demonstrate that actions and objects that are goal-relevant are construed more concretely than actions and objects that are not. Importantly, however, we did not find that the construal of goal-irrelevant stimuli is also affected (Experiment 2). Thus, our effects cannot be due to a general shift an abstraction based on temperature (as suggested by IJzerman et al. 2014; IJzerman and Semin 2009). We also did not expect a temperature effect on the the general style of thinking, because approach motivation causes a more global processing style whereas avoidance motivation causes a more local processing style (Derryberry and Tucker 1994; Easterbrock 1959; Friedman and Förster 2001; Tyler and Tucker 1982). It is psychologically extremely adaptive to think globally when trying to reach a goal, as global attention helps to not to miss relevant information that may help to reach one's goal. However, we argue that, as soon as goalrelevant stimuli (actions, people, or objects) are available, people switch to a concrete construal of these stimuli. A general global, abstract style of thinking may help to identify goal-relevant stimuli, but a concrete, local representation helps to act towards the stimuli. Such dynamics of motivated construal and its shift have not been investigated so far and may constitute a fruitful direction for follow-up research.

The present research used temperature as a factor to manipulate motivational states. It is an open question, though, whether other motivations besides reducing warmth or cold also affect level of construal. For instance, does hunger trigger a concrete construal of food? And can more abstract motivations, such as achievement motivation or power motivation, also affect construal level of goal-relevant stimuli? We suggest that this may well be the case, although data on these questions are still pending.

Motivational effects on one's level of construal have wide and interesting implications. For instance, motivations could shift product evaluations, as has been shown in Experiment 3. Additionally, construal level can affect visual versus verbal modes of processing (Amit et al. 2012), similarity versus differences focus (Förster et al. 2008), and perceptions of prototypicality (Liberman et al. 2002). Motivational effects on construal could have further downstream consequences, for instance on the experiences of time (Hansen and Trope 2013), duration prediction (Kanten 2011), politeness (Stephan et al. 2010), integrative versus distributive solutions in negotiations (Henderson and Trope 2009), or imitation (Hansen et al. 2016; Wessler and Hansen 2017). Could it be, for instance, that the motivation to approach a person reduces formal politeness (as a sign of a more concrete construal of the interaction) towards this person? Or does a strong motivation to get a certain outcome in a negotiation lead to a more distributive (concrete) negotiation style? Investigation of such construal-related downstream consequences may be a promising avenue for future research.

The present findings show how motivations can affect judgments. Not only do motivations influence the content of one's thoughts, they also change one's level of construal. Motivation to approach objects and actions that help reducing a visceral state triggers a concrete construal of these objects and action, presumably in order to prepare an adaptive response.

Acknowledgements Open access funding provided by Paris Lodron University of Salzburg. The authors thank Sabrina Klein, Clara Mildenberger, Jessica Napieralski, Jana Schmidt, Philip Weber, Helena Weitzel, and Tabea Zorn for their help with creating the study materials and conducting the studies.

\section{Compliance with ethical standards}

Conflict of interest Both authors declare that they have no conflict of interest.

Ethical approval All procedures performed in studies involving human participants were in accordance with the ethical standards of the institutional and/or national research committee and with the 1964 Helsinki declaration and its later amendments or comparable ethical standards.

Informed consent Informed consent was obtained from all individual participants included in the studies.

Open Access This article is distributed under the terms of the Creative Commons Attribution 4.0 International License (http://creativeco mmons.org/licenses/by/4.0/), which permits unrestricted use, distribution, and reproduction in any medium, provided you give appropriate credit to the original author(s) and the source, provide a link to the Creative Commons license, and indicate if changes were made.

\section{References}

Aarts, H. (2012). Goals, motivated social cognition and behavior. In S. T. Fiske \& C. N. Macrae (Eds.), Sage handbook of social cognition (pp. 75-79). London: Sage. https://doi.org/10.4135/97814 46247631.n5.

Alter, A., \& Balcetis, E. (2011). Fondness makes the distance grow shorter: Desired locations seem closer because they seem more vivid. Journal of Experimental Social Psychology, 47, 16-21. https://doi.org/10.1016/j.jesp.2010.07.018.

Amit, E., Wakslak, C. J., \& Trope, Y. (2012). The use of visual and verbal means of communication across psychological distance. Personality and Social Psychology Bulletin, 39, 43-56. https:// doi.org/10.1177/0146167212460282.

Bagozzi, R. B. (1992). The self-regulation of attitudes, intentions, and behavior. Social Psychology Quarterly, 55, 178-204. https://doi. org/10.2307/2786945. 
Balcetis, E. (2016). Approach and avoidance as organizing structures for motivated distance perception. Emotion Review, 8, 115-128. https://doi.org/10.1177/1754073915586225.

Balcetis, E., \& Dunning, D. (2006). See what you want to see: Motivational influences on visual perception. Journal of Personality and Social Psychology, 91, 612-625. https://doi. org/10.1037/0022-3514.91.4.612.

Balcetis, E., \& Dunning, D. (2010). Wishful seeing: Desired objects are seen as closer. Psychological Science, 21, 147-152. https:// doi.org/10.1177/0956797609356283.

Bandura, A. (1991). Social cognitive theory of self-regulation. Organizational Behavior and Human Decision Processes, 50, 248-287. https://doi.org/10.1016/0749-5978(91)90022-L.

Bruchmann, K., \& Evans, A. T. (2013). Abstract mind-sets and social comparison: When global comparisons matter. Social Psychological and Personality Science, 4, 427-433. https://doi. org/10.1177/1948550612464661.

Burgoon, E. M., Henderson, M. D., \& Markman, A. B. (2013). There are many ways to see the forest for the trees: A tour guide for abstraction. Perspectives on Psychological Science, 8, 501-520. https://doi.org/10.1177/1745691613497964.

Carver, C. S., \& Scheier, M. F. (1981). Attention and self-regulation. New York: Springer. https://doi. org/10.1007/978-1-4612-5887-2.

Carver, C. S., \& Scheier, M. F. (2016). Self-regulation of action and affect. In K. D. Vohs \& R. F. Baumeister (Eds.), Handbook of self-regulation: Research, theory, and applications (Vo (3, pp. 3-23). New York: Guilford.

Changizi, M. A., \& Hall, W. G. (2001). Thirst modulates a perception. Perception, 30, 1489-1497. https://doi.org/10.1068/p3266.

Cole, S., \& Balcetis, E. (2013). Sources of resources: Bioenergetic and psychoenergetic resources influence distance perception. Social Cognition, 31, 721-732. https://doi.org/10.1521/ soco.2013.31.6.721.

Cole, S., Balcetis, E., \& Dunning, D. (2013). Affective signals of threat increase perceived proximity. Psychological Science, 24, 34-40. https://doi.org/10.1177/0956797612446953.

Cole, S., Riccio, M., \& Balcetis, E. (2014). Focused and fired up: Narrowed attention produces perceived proximity and increases goal-relevant action. Motivation \& Emotion, 38, 815-822. https ://doi.org/10.1007/s11031-014-9432-3.

Derryberry, D., \& Tucker, D. M. (1994). Motivating the focus of attention. In P. M. Niedenthal \& S. Kitayama (Eds.), The heart's eye: Emotional influences in perception and attention (pp. 167196). Cambridge: Academic Press. https://doi.org/10.1016/ B978-0-12-410560-7.50014-4.

Dunning, D., \& Balcetis, E. (2013). Wishful seeing: How preferences shape visual perception. Current Directions in Psychological Science, 22, 33-37. https://doi.org/10.1177/0963721412463693.

Easterbrook, J. A. (1959). The effect of emotion on cue utilization and the organization of behavior. Psychological Review, 66, 187-201. https://doi.org/10.1037/h0047707.

Faul, F., Erdfelder, E., Buchner, A., \& Lang, A.-G. (2009). Statistical power analyses using $\mathrm{G}^{*}$ Power 3.1: Tests for correlation and regression analyses. Behavior Research Methods, 41, 11491160. https://doi.org/10.3758/BRM.41.4.1149.

Fiske, S. T. (1993). Social cognition and social perception. Annual Review of Psychology, 44, 155-194. https://doi.org/10.1146/ annurev.ps.44.020193.001103.

Fiske, S. T. (2010). Social beings: Core motives in social psychology (2nd edn.). New York: Wiley.

Förster, J., Liberman, N., \& Kuschel, S. (2008). The effect of global versus local processing styles on assimilation versus contrast in social judgment. Journal of Personality and Social Psychology, 94, 579-599. https://doi.org/10.1037/0022-3514.94.4.579.
Friedman, R. S., \& Förster, J. (2001). The effects of promotion and prevention cues on creativity. Journal of Personality and Social Psychology, 81, 1001-1013. https://doi. org/10.1037/0022-3514.81.6.1001.

Fujita, K., Trope, Y., Liberman, N., \& Levin-Sagi, M. (2006). Construal level and self-control. Journal of Personality and Social Psychology, 90, 351-367. https://doi. org/10.1037/0022-3514.90.3.351.

Gollwitzer, P. M. (1993). Goal achievement: The role of intentions. In W. Stroebe \& M. Hewstone (Eds.), European review of social psychology (Vol (4, pp. 141-185). Chichester: Wiley.

Gollwitzer, P. M. (1999). Implementation intentions: Strong effects of simple plans. American Psychologist, 54, 493-503. https:// doi.org/10.1037/0003-066X.54.7.493.

Gollwitzer, P. M., \& Moskowitz, G. (1996). Goal effects on thought and behavior. In E. T. Higgins \& A. Kruglanski (Eds.), Social psychology: Handbook of basic principles (pp. 361-399). New York: Guilford Press.

Halali, E., Meiran, N., \& Shalev, I. (2017). Keep it cool: Temperature priming effect on cognitive control. Psychological Research, 81 , 343-354. https://doi.org/10.1007/s00426-016-0753-6.

Hansen, J., Alves, H., \& Trope, Y. (2016). Psychological distance reduces literal imitation: Evidence from an imitation-learning paradigm. Journal of Experimental Psychology: Human Perception and Performance, 42, 320-330. https://doi.org/10.1037/ xhp0000150.

Hansen, J., \& Melzner, J. (2014). What you hear shapes how you think: Sound patterns change level of construal. Journal of Experimental Social Psychology, 54, 131-138. https://doi. org/10.1016/j.jesp.2014.05.002.

Hansen, J., Rim, S., \& Fiedler, K. (2013). Psychological distance and judgments of causal impact. Journal of Experimental Social Psychology, 49, 1184-1189. https://doi.org/10.1016/j. jesp.2013.05.012.

Hansen, J., \& Trope, Y. (2013). When time flies: How abstract and concrete mental construal affect the perception of time. Journal of Experimental Psychology: General, 142, 336-347. https:// doi.org/10.1037/a0029283.

Hastorf, A. H., \& Cantril, H. (1954). They saw a game: A case study. The Journal of Abnormal and Social Psychology, 49, 129-134. https://doi.org/10.1037/h0057880.

Henderson, M. D., \& Trope, Y. (2009). The effects of abstraction on integrative agreements: When seeing the forest helps avoid getting tangled in the trees. Social Cognition, 27, 399-415. https ://doi.org/10.1521/soco.2009.27.3.402.

IJzerman, H., Leung, A. K. Y., \& Ong, L. S. (2014). Perceptual symbols of creativity: Coldness elicits referential, warmth elicits relational creativity. Acta Psychologica, 148, 136-147. https:// doi.org/10.1016/j.actpsy.2014.01.013.

IJzerman, H., \& Semin, G. R. (2009). The thermometer of social relations: Mapping social proximity on temperature. Psychological Science, 20, 1214-1220. https://doi.org/10.111 1/j.1467-9280.2009.02434.x.

Isen, A. M., \& Daubman, K. A. (1984). The influence of affect on categorization. Journal of Personality and Social Psychology, 47, 1206-1217. https://doi.org/10.1037/0022-3514.47.6.1206.

Kanten, A. B. (2011). The effect of construal level on predictions of time duration. Journal of Experimental Social Psychology, 47, 1037-1047. https://doi.org/10.1016/j.jesp.2011.04.005.

Kivetz, R., Urminsky, O., \& Zheng, Y. (2006). The goal-gradient hypothesis resurrected: Purchase acceleration, illusionary goal progress, and customer retention. Journal of Marketing Research, 43, 39-58.

Kogut, T., \& Ritov, I. (2005). The "identified victim" effect: An identified group, or just a single individual? Journal of Behavioral Decision Making, 18, 157-167. 
Kunda, Z. (1990). The case for motivated reasoning. Psychological Bulletin, 108, 480-498. https://doi. org/10.1037/0033-2909.108.3.480.

Latham, G. P., \& Locke, E., A (1991). Self-regulation through goal setting. Organizational Behavior and Human Decision Processes, 50, 212-247. https://doi.org/10.1016/0749-5978(91)90021-K.

Ledgerwood, A., Wakslak, C. J., \& Wang, M. A. (2010). Differential information use for near and distant decisions. Journal of Experimental Social Psychology, 46, 638-642. https://doi.org/10.1016/j. jesp.2010.03.001.

Lee, A. Y., Keller, P. A., \& Sternthal, B. (2010). Value from regulatory construal fit: The persuasive impact of fit between consumer goals and message concreteness. Journal of Consumer Research, 36, 735-747. https://doi.org/10.1086/605591.

Lee, L., \& Ariely, D. (2006). Shopping goals, goal concreteness, and conditional promotions. Journal of Consumer Research, 33, 60-70. https://doi.org/10.1086/504136.

Liberman, N., Sagristano, M. D., \& Trope, Y. (2002). The effect of temporal distance on level of mental construal. Journal of Experimental Social Psychology, 38, 523-534. https://doi.org/10.1016/ S0022-1031(02)00535-8.

Locke, E. A., Chah, D. O., Harrison, D. S., \& Lustgarten, N. (1989). Separating the effects of goal specificity from goal level. Organizational Behavior and Human Decision Processes, 43, 270-287. https://doi.org/10.1016/0749-5978(89)90053-8.

Locke, E. A., \& Latham, G. P. (1990). Work motivation and satisfaction: Light at the end of the tunnel. Psychological Science, 4, 240-246. https://doi.org/10.1111/j.1467-9280.1990.tb00207.x.

Loewenstein, G. (1996). Out of control: Visceral influences on behavior. Organizational Behavior and Human Decision Processes, 65, 272-292. https://doi.org/10.1006/obhd.1996.0028.

Medin, D. L., \& Smith, E. E. (1984). Concepts and concept formation. Annual Review of Psychology, 35, 113-138. https://doi. org/10.1146/annurev.ps.35.020184.000553.

Mento, A. J., Steel, R. P., \& Karren, R. J. (1987). A meta-analytic study of the effects of goal setting on task performance: 1966-1984. Organizational Behavior and Human Decision Processes, 39, 52-83. https://doi.org/10.1016/0749-5978(87)90045-8.

Rim, S., Hansen, J., \& Trope, Y. (2013). What happens why? Psychological distance and focusing on causes versus consequences of events. Journal of Personality and Social Psychology, 104, 457-472. https://doi.org/10.1037/a0031024.

Rosch, E. (1975). Cognitive representations of semantic categories. Journal of Experimental Psychology: General, 104, 192-233. https://doi.org/10.1037/0096-3445.104.3.192.

Rosch, E. (1978). Principles of categorization. In E. Rosch \& B. B. Lloyd (Eds.), Cognition and Categorization (pp. 27-48). Hillsdale: Erlbaum.

Semin, G. R., \& Fiedler, K. (1988). The cognitive functions of linguistic categories in describing persons: Social cognition and language. Journal of Personality and Social Psychology, 54, 558-568. https://doi.org/10.1037/0022-3514.54.4.558.

Semin, G. R., \& Fiedler, K. (1991). The linguistic category model, its bases, applications and range. European Review of Social Psychology, 2, 1-30. https://doi.org/10.1080/14792779143000006.

Shapira, O., Liberman, N., Trope, N., \& Rim, S. (2012). Levels of mental construal: Separating the primary from the secondary. In S. T. Fiske \& C. N. Macrae (Eds.), Sage handbook of social cognition (pp. 229-250). New York: Sage Publications. https://doi. org/10.4135/9781446247631.n12.

Showers, C., \& Cantor, N. (1985). Social cognition: A look at motivated strategies. Annual Review of Psychology, 36, 275-305. https ://doi.org/10.1146/annurev.ps.36.020185.001423.

Stefanucci, J. K., Proffitt, D. R., Clore, G. L., \& Parekh, N. (2008). Skating down a steeper slope: Fear influences the perception of geographical slant. Perception, 37, 321-323. https://doi. org/10.1068/p5796.

Steinmetz, J., \& Mussweiler, T. (2011). Breaking the ice: How physical warmth shapes social comparison consequences. Journal of Experimental Social Psychology, 47, 1025-1028. https://doi. org/10.1016/j.jesp.2011.03.022.

Steinmetz, J., \& Posten, A. C. (2017). Physical temperature affects response behavior. Journal of Experimental Social Psychology, 70, 294-300. https://doi.org/10.1016/j.jesp.2016.12.001.

Steinmetz, J., Tausen, B. M., \& Risen, J. L. (2018). Mental simulation of visceral states affects preferences and behavior. Personality and Social Psychology Bulletin, 44, 406-416. https://doi. org/10.1177/0146167217741315.

Stephan, E., Liberman, N., \& Trope, Y. (2010). Politeness and psychological distance: A construal level perspective. Journal of Personality and Social Psychology, 98, 268-280. https://doi.org/10.1037/ a0016960.

Trope, Y., \& Liberman, N. (2003). Temporal construal. Psychological Review, 110, 403-421. https://doi. org/10.1037/0033-295X.110.3.403.

Trope, Y., \& Liberman, N. (2010). Construal-level theory of psychological distance. Psychological Review, 117, 440-463. https://doi. org/10.1037/a0018963.

Tubbs, M. E. (1986). Goal setting: A meta-analytic examination of the empirical evidence. Journal of Applied Psychology, 71, 474-483. https://doi.org/10.1037/0021-9010.71.3.474.

Tyler, S. K., \& Tucker, D. M. (1982). Anxiety and perceptual structure: Individual differences in neuropsychological function. Journal of Abnormal Psychology, 91, 210-220. https://doi. org/10.1037/0021-843X.91.3.210.

Valdés-Conroy, B., Román, F. J., Hinojosa, J. A., \& Shorkey, S. P. (2012). So far so good: Emotion in the peripersonal/extrapersonal space. PloSOne, 7(11), e49162. https://doi.org/10.1371/journ al.pone.0049162.

Vallacher, R. R., \& Wegner, D. M. (1987). What do people think they're doing? Action identification and human behavior. Psychological Review, 94, 3-15. https://doi.org/10.1037/0033-295X.94.1.3.

Vallacher, R. R., \& Wegner, D. M. (1989). Levels of personal agency: Individual variation in action identification. Journal of Personality and Social Psychology, 57, 660-671. https://doi. org/10.1037/0022-3514.57.4.660.

Wakslak, C. J., \& Trope, Y. (2009). The effect of construal level on subjective probability estimates. Psychological Science, 20, 52-58. https://doi.org/10.1111/j.1467-9280.2008.02250.x.

Wessler, J., \& Hansen, J. (2017). Temporal closeness promotes imitation of meaningful gestures in face-to-face communication. Journal of Nonverbal Behavior, 41, 415-431. doi:0.1007/ s10919-017-0256-1.

Zhang, Y., \& Risen, J. L. (2014). Embodied motivation: Using a goal systems framework to understand the preference for social and physical warmth. Journal of Personality and Social Psychology, 107, 965-977. https://doi.org/10.1037/a0038153.

Zimmerman, B. J. (2000). Attaining self-regulation: A social-cognitive perspective. In M. Boekaerts, P. R. Pintrich \& M. Zeidner (Eds.), Handbook of self-regulation: Theory, research, and applications (pp. 13-39). San Diego: Academic Press. https://doi.org/10.1016/ B978-012109890-2/50031-7.

Publisher's Note Springer Nature remains neutral with regard to jurisdictional claims in published maps and institutional affiliations. 